Altunbay, M. ve Uslu Üstten, A. (2020). Okuma kültürünün bir göstergesi olarak kitaplık ve kütüphane kullanımı üzerine bir araştırma. Ana Dili Eğitimi Dergisi, 8(3), 916-930.

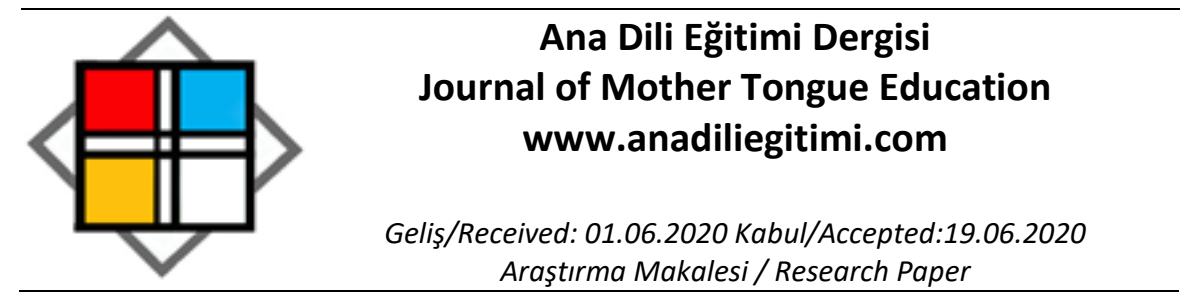

\title{
Okuma Kültürünün Bir Göstergesi Olarak Kitaplık ve Kütüphane Kullanımı Üzerine Bir Araştırma*
}

\author{
Müzeyyen ALTUNBAY* \\ Aliye USLU ÜSTTEN ${ }^{* *}$
}

\begin{abstract}
Öz
Okuma kültürü, toplumların gelişmişlik göstergelerinden biridir. Okuma kültürünün ortaya konmasında satılan ve basılan kitap sayısı, kişi başına okunan ortalama kitap sayısı, okunan gazete sayısı vb. gibi ölçütler alınabilir. Bununla birlikte bir toplumdaki kütüphane sayısı ve kütüphanelerin kullanımı ile evlerde kitaplık ya da kütüphane bulunması da okuma kültürünü belirleyen ölçütler arasında gösterilir. Bu çalışmada kütüphanelerin öneminden hareketle ilköğretim öğrencilerinin kütüphane kullanımları, evlerinde kitaplık/kütüphane bulunma durumları ile okuma alışkanlıkları arasındaki ilişkinin ortaya konması amaçlanmıştır. Çalışmada araştırma yöntemlerinden tarama (survey) kullanılmıştır. Araştırmanın sonuçlarına göre öğrencilerin okuma kültürü ve kitaplık/kütüphane kullanmaları arasında önemli bir ilişki vardır. Evinde, sınıfında, okulunda ve yaşadığı bölgede kitaplık veya kütüphane bulunan öğrenciler ile aileleri kitap okuyan, evde kitap okuma saatlerine katılan öğrencilerin de okumaya karşı tutumlar olumlu gelişmektedir. Bu nedenle kütüphaneler, günümüz çocuklarına, gençlerine ve yetişkinlere hitap edecek şekilde yeniden çok yönlü olarak tasarlanmalıdır.
\end{abstract}

Anahtar Kelimeler: okuma kültürü, okuma alışkanlığı, kütüphane.

\begin{abstract}
A Study on the Use of Library as an Indicator of Reading Culture
Abstract

Reading culture is one of the development indicators of societies. The number of books sold and published, the average number of books read per person, the number of newspapers read, etc. can be taken as criteria in the presentation of the reading culture. However, the number of libraries in a society and the use of them and the presence of a library in the home are also among the criteria that determine the reading culture. In this study, it is aimed to reveal the relationship between the use of libraries, presence of a library at home and reading habits. Survey method, one of the research methods, was used in the study. According to the results of the research, there is an important relationship between students' reading culture and library use. For this reason, libraries should be redesigned so as to appeal to today's children, teens and adults.
\end{abstract}

Keywords: Reading culture, reading habit, library.

\section{Giriş}

Her türlü bilimsel gelişim ve değişim (sanayi, askeri, ekonomik, siyasi, sağlık vb. alanlarda), okumanın neticesinde ortaya çıkar. Bir toplumun okuma eylemini kültüre dönüştürmesi için bireysel olarak okuma alışkanlığının kazanıımış olması gerekir. "Okuma zevk ve alışkanlığı ailede başlamakta

\footnotetext{
*Araştırmanın etik kurulu izni: 22.05.2018 tarihli karar, 29409993-605.01-E.9989684 sayılı belge.

* Doç. Dr. Müzeyyen Altunbay, Giresun Üniversitesi, Eğitim Fakültesi, Türkçe ve Sosyal Bilimler Eğitimi Bölümü, Türkçe Eğitimi Ana Bilim Dalı, Giresun, altun.bay@hotmail.com, ORCID: orcid.org/0000-0002-9568-3160

** Doç. Dr. Aliye Uslu Üstten, Gazi Üniversitesi Gazi Eğitim Fakültesi, Türkçe Eğitimi Ana Bilim Dalı, Ankara, aliyeuslu@gazi.edu.tr, ORCID: orcid.org/0000-0002-2937-6154
} 
ve büyük ölçüde okul ortamında olgunlaşmaktadır. Bu açıdan bakıldığında okul kütüphanelerinin önemi daha da artmaktadır. Okuma alışkanlığı ve kütüphane kullanımı, bireysel açıdan olduğu kadar toplumsal açıdan da bir geliş̧mişlik ile refah seviyesi kriteri sayılmaktadır” (Aydoğdu, 2020: 203).

Ortaş (2014) Türkiye'de okuma oranın düşük olduğuna, okumanın temel ihtiyaç olarak görülmediğine dikkat çekerken ders dışı okumanın azlığına ve eğitimli kesimin de okumayı yaşam tarzı hâline getirmediğini belirtmektedir. Okuma kültürü, bir ülkenin eğitim ve gelişmişlik düzeyini gösterir. Okuma kültürünün kazanılması ve geliştirilmesi süreç gerektiren bir iştir. Bu süreçte başta ebeveynler olmak üzere sınıf öğretmenleri, okul yönetimi ve kütüphanelere önemli görevler düşmektedir.

Okuma alıskanlığı ile sıklıkla karıştırılan bir kavram olan okuma kültürü, okuma eyleminin toplumsal yönüne işaret eder. Alışkanlık bireysel iken kültür, kolektif bir yapılanmanın neticesinde ortaya çıkar. Örneğin bir kişinin düzenli kitap okuması, kitap satın alması alışkanlık olarak değerlendirilirken, o toplumun kitap okuma oranının yüksek olması, entelektüel birikimlerinin olması kültür olarak ifade edilebilir. Okuma kültürünün ortaya konmasında satılan ve basılan kitap sayısı, kişi başına okunan ortalama kitap sayısı, okunan gazete sayısı vb. gibi ölçütler alınabilir. Bununla birlikte bir toplumdaki kütüphane sayısı ve kütüphanelerin kullanımı ile evlerde temel bir ihtiyaç olarak görülüp alınan kitaplıklar ya da kurulan kütüphaneler de okuma kültürünü belirleyen ölçütler arasında gösterilir.

\section{Okuma Kültürü ve Kütüphane ilişkisi}

Kültür ve Turizm Bakanlığının Türkiye'deki okur profili ve eğilimlerinin, toplumdaki kütüphane algısının belirlenmesi, bilgiye erişimde dolaylı veya dolaysız karşılaşılan sorunların giderilmesi gibi amaçlarla yaptığı araştırmada Türkiye'nin okuma kültürüne ilişkin veriler toplanmıştır (Kültür ve Turizm Bakanlığı, 2019). "Türkiye Okuma Kültürü Haritası Projesi" kapsamında Adana, Ağrı, Ankara, Antalya, Aydın, Balıkesir, Bursa, Erzurum, Gaziantep, Hatay, İstanbul, İzmir, Kastamonu, Kayseri, Kırıkkale, Kocaeli, Konya, Malatya, Manisa, Mardin, Samsun, Şanlıurfa, Tekirdağ, Trabzon, Van ve Zonguldak illerini kapsayan 26 ilde 6212 kişi ile görüşülmüştür. Araştırmaya katılanlardan 7-14 yaş grubundaki bireyler (\% 35.4) seçici ve düzenli okumaktadırlar. Kitap, bu okumalar içerisinde en çok okunan (\% 54) basılı materyaldir. En çok kitap okuyan grup, öğrencilerdir. Bunlar arasında 7-14 yaş grubundaki bireyler \% 87.5 orana sahiptir. Araştırma verilerine göre Türkiye'de yılda okunan kitap sayısı 7,2 oranındadır ve tavsiye yoluyla yapılan okumalar ağırlıktadır. Öğrenciler yılda ortalama 11.1 kitap okumakta, 7-14 yaş grubu bireyler ise yılda ortalama 12 kitap okumaktadırlar. Halk kütüphanelerin varlığının bilinme oranı \% 77'dir. Halk kütüphanelerini bilmeyenler arasında yılda ortalama 41-50 kitap satın alanlar (\% 34.5), evinde 151'den fazla kitap bulunduranlar (\% 26.5), seçici ve düzensiz okuyanlar (\% 23.9), hiç kitap okumayanlar (\% 32.9) ve evinde internet bağlantısı bulunanlar (\% 24.3) orana sahiptir. Halk kütüphanelerinden yararlanma ihtiyacı duymayanların belirttiği nedenler şu şekildedir:

1. Kütüphane kullanma alışkanlığım yok (\% 43.5)

2. Okumayı sevmiyorum (\% 16.2)

3. Bilgi ihtiyacımı internetten karşılıyorum (\% 12.1)

4. Kütüphaneyi sevmiyorum (\% 9.4)

5. Diğer kütüphanelerden yararlanıyorum (\% 6.2)

6. Zamanım yok (\% 4.1)

7. Kütüphane uzak/Yerini bilmiyorum/ Kütüphane yok (\% 4.6)

Türkiye'de okuma kültürü ya da okuma alışkanlığı üzerine yapılan çalışmalarda sıklıkla kütüphane kullanım oranına yer verilmesi, okuma kültürü ile kütüphanelerin kullanımı arasındaki ilişkiyi göstermesi bakımından önemlidir. Kütüphanelerin etkisini ve kapsamını artırmaya yönelik çalışmalarda da okuma alışkanlığının kültüre dönüşmesi amaçlanır. Bu çalışmalardan biri de 26-27 Mayıs 2016 tarihlerinde Antalya'da gerçekleştirilen "Herkes için Kütüphane Projesi"dir. Projenin amacı, belediyelere ait kütüphane ve bilgi merkezlerinin vatandaşlar için birer cazibe merkezi hâline dönüşmesini sağlamaya çalışmak şeklinde belirlenmiştir. Bill ve Melinda Gates Vakfı tarafından desteklenen bu proje, Hacettepe Üniversitesi Teknokent-Teknoloji Transfer Merkezi ev sahipliğinde yürütülmektedir. Projenin paydaşları arasında Türk Kütüphaneciler Derneği (TKD), Türkiye Bilişim 
Derneği (TBD), Yakın Doğu Üniversitesi (YDÜ), Türkiye Küçük ve Orta Ölçekli İşletmeler, Serbest Meslek Mensupları ve Yöneticiler Vakfı (TOSYÖV) yer almaktadır (Al; Doğan; Soydal; Taşkın, 2017: 1314).

Dünyada ise kütüphanelerin etkisini güçlendirmeye yönelik çalışmalar mevcuttur. Bunlardan biri UNESCO tarafından yayımlanan Halk Kütüphanesi Bildirgesi'dir. Bildirgede, "okuryazarlık; eğitim, bilgi ve kütüphaneler ile buralardaki bilgi hizmetlerinin kullanımı için anahtar olduğundan, halk kütüphanesi okuryazarlık kampanyalarını etkin bir biçimde desteklemelidir. Yeni okuryazar insanlar becerilerini yaşatmak ve geliştirmek için uygun okuma materyallerine kolay erişim gereksinimi duyarlar" (www.ifla.org) ifadelerine yer verilmektedir. Aynı bildirgede halk kütüphanelerinin amaçları ortaya konmuş, kapsamlı bir analiz yapılmıştır. "Halk kütüphanesi, toplumdaki bütün grupların gereksinimlerini yaş, fiziksel, ekonomik ya da toplumsal durum farkı gözetmeksizin karşılamayı amaçlar. Ancak çocukların ve gençlerin gereksinimlerini karşılamada onun, özel bir sorumluluğu vardır. Eğer çocuklar küçük yaşta bilginin heyecanını tadar ve hayal gücü ürünü çalışmalardan etkilenirlerse yaşamları boyunca kendilerini zenginleştirerek ve topluma katkıda bulunarak bu çok önemli kişisel gelişim ögelerinden yararlanırlar. Ayrıca çocuklar, anne babalarını ve diğer yetişkinleri kütüphane kullanımı konusunda teşvik edebilirler. Okumayı öğrenmede zorluk çeken çocukların uygun materyal sağlamak için kütüphaneyi kullanmaları çok önemlidir" (IFLA/UNESCO, 2004, 29-30) denilerek kütüphanelerin ulaşılabilir olmasına ve sağladığı katkılara değinilmiştir. Kajberg ise halk kütüphanelerinin toplumdaki rolünün artırılması gerektiğine işaret ederek kütüphaneleri "neo-liberal toplumdaki büyüyen demokrasi açığı konusunda ve toplumları küresel açıdan ilgilendiren çeliş̧iler, krizler ve zorluklar hususunda farkındalık getiren bir kuruma dönüştürme" konusunu ele alır (Kajberg, 2013: 254).

Günümüzde kütüphanelerin işlevlerinin farklılaştığı, değişen ihtiyaçlara göre yeniden düzenlenmesi gerektiği bilinmektedir. Yalçınkaya (2016) dijital kütüphaneleri ele alarak artık dijital kütüphanelerin, kültürün bir parçası olması gerektiğini savunur. "Küresel bilme ve kitlesel bilgelik açısından etkin ve etkili varoluşun yeni yüzü dijital kütüphanelerdir. Dijital kütüphaneler; dijital yaşam içerisinde üretilen bilgileri sistemli bir bütünlük içerisinde yeniden edinerek ve kullanıma sunarak dijital kültürün hem parçası hem de planlayıcısı olmaktadır" (Yalçınkaya, 2016: 614). Ancak bir ildeki halk kütüphaneleri, belediye kütüphaneleri veya diğer kamu kurum kuruluşlarına ya da vakıflara ait kütüphaneler ile okuma salonları, okuma kültürünün oluşmasında önemli yerlerdir. Özellikle maddi imkânı yetersiz olan öğrencilerin araştırma-geliştirme gibi amaçlarla çeşitli kaynaklara ulaşmalarında kütüphanelerin önemi göz ardı edilemez. İ veya ilçelerdeki çocuk kütüphaneleri de bu bağlamda önemli yerlerdir. "Çocuk kütüphanesi ziyareti bir çocuğun öğrenmeye ilgi duymasını sağlamanın en iyi yollarından biridir. Kütüphaneler çocukların hayal güçlerini harekete geçirmek, kitaplar ve okuryazarlık programlarıyla ilgilenmelerini sağlamak içi tasarlanmıştır. Çocukları eğitme ve kitaplara karşı heyecan duymalarını sağlama konusunda önemli bir rol oynamaktadır" (Cevher, 2015).

Cevher'e göre çocuk kütüphaneleri bireylerin yaşamları boyunca sürdürecekleri kütüphane kullanma alışkanlığının inşa edilmesinde ilk aşamadır. Bu alışkanlığın temelinin atıldığı kütüphane türüdür. Çocuk kütüphanesi çocuklarda okuma zevkinin başlamasını sağlayan, çocuğu kitapla bir okuma atmosferi içinde belki de ilk kez buluşturan kurumdur. Çocuk kütüphanesi, çocuğun hayal gücünü ve diğer yaratıcı güçlerini oluşturan/geliştiren kütüphanedir. Çocuk kütüphanesi, çocuğun bilgiyle ilişkisinin, bilgiye erişme becerisinin temellerini atan kuruluştur" (Cevher, 2015: 18). Bu nedenle bu çalışmada kütüphanelerin öneminden hareketle ilköğretim öğrencilerinin kütüphane kullanımları, evlerinde kitaplık/kütüphane bulunma durumları ile okuma alışkanlıkları arasındaki ilişkinin ortaya konması amaçlanmıştır. Maddi imkânlar dâhilinde evlerde kütüphane veya kitaplık bulunması da okuma kültürünün önemli bir göstergesidir. Okumaya verilen değeri göstermekle birlikte ailede okuma alışkanlığının olduğunu ortaya koymaktadır.

Araştırmanın temel amacı; ilköğretim öğrencilerinin okuma kültürünün bir göstergesi olarak kitaplık/kütüphanelerin kullanımına ilişkin görüşlerini belirleyebilmektir. Bu temel amaca bağıı olarak belirlenen alt amaçlar ise öğrencilerin;

1. Cinsiyetleri ile okuma kültürü ve kitaplık/kütüphanelerin kullanımı arasında bir ilişki var mıdır? 
2. Anne-babalarının eğitim durumu ile okuma kültürü ve kitaplık/kütüphanelerin kullanımı arasında bir ilişki var mıdır?

3. Evlerinde okuma saati yapılması ile okuma kültürü ve kitaplık/kütüphanelerin kullanımı arasında bir ilişki var mıdır?

4. Okudukları kitap sayısı ile okuma kültürü ve kitaplık/kütüphanelerin kullanımı arasında bir ilişki var mıdır?

\section{Araştırmanın Modeli}

\section{Yöntem}

Bu çalışma betimsel nitelikte bir araştırmadır. Çalışmada araştırma yöntemlerinden tarama (survey) modeli kullanılmıştır. Karasar’a (2012: 7) göre tarama modelleri, "geçmişte ya da hâlen var olan bir durumu var olduğu şekliyle betimlemeyi amaçlayan araştırma yaklaşımlarıdır. Araştırmaya konu olan olay, birey ya da nesne kendi koşulları içinde ve olduğu gibi tanımlanmaya çalışılır." Araştırmacının hedefi, problem tespit etmek ve verilerden hareketle ortaya çıkarmaktır.

\section{Örneklem / Araştırma grubu}

Bu çalışma, Giresun ili Merkez ilçesinde öğrenim görmekte olan toplam 175, 5. sınıf öğrencisi ile yapılmıştır. Çalışma, 2018 yılının Bahar döneminde gerekli izinler alınarak yürütülmüştür.

Tablo 1.

Öğrencilerin Demografik Özellikleri

\begin{tabular}{lcc} 
& $f$ & $\%$ \\
\hline Cinsiyet & & \\
\hline Erkek & 84 & 48,0 \\
Kız & 91 & 52,0 \\
\hline Yaş & & \\
\hline 9 yaş & 1 &, 6 \\
10 yaş & 55 & 31,4 \\
11 yaş & 110 & 62,9 \\
12 yaş & 7 & 4,0 \\
13 yaş & 2 & 1,1 \\
\hline Toplam & 175 & 100,0 \\
\hline
\end{tabular}

Tablo 1'de katılımcıların cinsiyetlerine ilişkin dağılım incelendiğinde öğrencilerin \%52'sinin kız, \%48'inin ise erkek olduğu; \%62,9' unun 11, \%31,4'ünün 10, \%4'ünün 12, \% 1,1'inin 13, \%0,6'sının ise 9 yaşında olduğu görülmektedir.

\section{Veri Toplama Araçları}

Öğrencilerin kütüphane kullanımı ve okuma alışkanlığı arasındaki ilişkiyi tespit etmek amacıyla araştırmacılar tarafından anket geliştirilmiş̧ir. Anket maddeleri Türkçe Dersi Öğretim Programı'nda (MEB, 2019) okuma becerisi kazanımlarından yararlanılarak ve uzman görüşü alınarak hazırlanmıştır.

Anket, iki bölümden oluşmaktadır. Birinci bölümde kişisel bilgilere dayalı sorular yer almaktadır. Anketin ikinci bölümü katılımcıların okuma kültürü ve kitaplık/kütüphane kullanımına ilişkin maddelerden oluşmaktadır.

\section{Verilerin Analizi}

Araştırmada kullanılan "Okuma Kültürü ve Kitaplık/Kütüphane Kullanımı" formundan elde edilen verilerin değerlendirilmesinde SPSS 20 (Statistical Packages for Social Science) paket programı kullanılmıştır. Analiz için frekans, yüzde, ortalama, standart sapma, bağımsız gruplar T-testi ve ANOVA istatistik teknikleri kullanılmıştır. Ankette yer alan olumsuz maddelerdeki puanlar veriler girildikten 
sonra "her zaman=1", "sık sık=2", "ara sıra=3", "nadiren=4", "asla=5" olarak değiştirilmiştir. Tespit ve değerlendirmeler bulgular bölümünde tablolar üzerinden sunulmuştur.

\section{Geçerlik ve Güvenirlik}

25 maddeden oluşan anketin Cronbach Alpha $(\alpha)$ değeri ,74 olarak ölçülmüştür. Bu değer, $\alpha>0.7$ olduğundan ölçeğin güvenilir olduğunu göstermektedir.

\section{Etik Kurulu İzni}

Bu çalışmada araştırma ve yayın etiğine uyulmuştur. "Okuma Kültürünün Göstergesi Olarak Kitaplık ve Kütüphanelerin Kullanımı" konulu araştırmanın Merkez Çıtlakkale Ortaokulu, Mustafa Kemal Ortaokulu ve Kayadibi Ortaokulunda gerçekleştirilmesi amacıyla T.C. Giresun Valiliği ì Millî Eğitim Müdürlüğünden araştırma izni alınmıştır. Yasal iznin ardından veri toplama aracı; okul yönetiminin sorumluluğunda/gözetiminde ve okul yönetiminin planladığı çalışma takvimine göre yürütülmüş, çalışmalara katıım gönüllülük esasına dayalı olarak sağlanmıştır.

Kurul adı = il Millî Eğitim Müdürlüğü

Karar tarihi $=22.05 .2018$

Belge sayı numarası= 29409993-605.01-E.9989684

\section{Bulgular}

Bu bölümde çalışmanın sonucunda elde edilen bulgulara ve bunlara ilişkin yorumlara yer verilmiştir. Öğrencilerin kitaplık/kütüphane kullanımı ve okuma alışkanlıkları arasındaki ilişki ile ilgili bulgular ve araştırmanın alt amaçları ele alınmıştır. Tablolarla gösterilen sonuçlar, ilgili literatürle karşılaştırılarak yorumlanmıştır.

Tablo 2.

Öğrencilerin Anne ve Babalarının Eğitim Durumuna ilişkin Bulgular

\begin{tabular}{lcccc}
\hline & \multicolumn{2}{c}{ Anne } & \multicolumn{3}{c}{ Baba } \\
Eğitim Durumu & $\mathrm{f}$ & $\%$ & $\mathrm{f}$ & $\%$ \\
\hline ilkokul & 54 & 30,9 & 44 & 25,1 \\
Ortaokul & 56 & 32,0 & 67 & 38,3 \\
Lise & 31 & 17,7 & 37 & 21,1 \\
Üniversite & 34 & 19,4 & 27 & 15,4 \\
\hline Toplam & 175 & 100,0 & 175 & 100,0 \\
\hline
\end{tabular}

Tablo 2'de öğrencilerin anne ve babalarının eğitim durumuna ait bulgular verilmektedir. Buna göre $54(\% 30,9)$ öğrencinin annesinin eğitim durumu ilkokul; $56(\% 32,0)$ öğrencinin annesinin eğitim durumu ortaokuldur. Annesi üniversite mezunu olan öğrenci sayısı $(34 / \% 19,4)$, annesi lise mezunu olan öğrenci sayısından $(31 / \% 17,7)$ daha fazladır. Öğrencilerin babalarının eğitim durumuna bakıldığında $44(\% 25,1)$ öğrencinin babasının eğitim durumu ilkokul; $67(\% 38,3)$ öğrencinin babasının eğitim durumu ortaokuldur. Babası lise mezunu olan öğrenci sayısı $37(\% 21,1)$ iken, babası üniversite mezunu olan öğrenci sayısı ise $27^{\prime}$ dir $(\% 15,4)$. Sonuç olarak annelerin üniversite mezuniyet oranı babaların oranından daha yüksektir.

Tablo 3.

Öğrencilerin "Kendinize ait bir kitaplık veya kütüphane olmasını ister misiniz?" Sorusuna Verdikleri Cevaplara ilişkin Bulgular

\begin{tabular}{lcc}
\hline & $\mathrm{f}$ & $\%$ \\
\hline Evet & 160 & 91,4 \\
Hayır & 15 & 8,6 \\
\hline Toplam & 175 & 100,0 \\
\hline
\end{tabular}


Tablo 3'te öğrencilerin kendilerine ait bir kitaplık veya kütüphane olmasını isteme durumlarına ilişkin bulgular yer almaktadır. Öğrencilerden 160'ı $(\% 91,4)$ kendilerine ait kitaplık veya kütüphane olmasını isterken $15^{\prime} \mathrm{i}(\% 8,6)$ istemediklerini belirtmiştir.

Tablo 4.

Kitaplık/Kütüphane Bulunma Durumuna ilişkin Bulgular

\begin{tabular}{lcccc}
\hline & Var & & \multicolumn{3}{c}{ Yok } \\
& $\mathrm{f}$ & $\%$ & $\mathrm{f}$ & $\%$ \\
\hline Evde & 127 & 72,6 & 48 & 27,4 \\
Sinıfta & 157 & 89,7 & 18 & 10,3 \\
Okulda & 169 & 96,6 & 6 & 3,4 \\
il/ilçede & 36 & 20,6 & 139 & 79,4 \\
\hline Toplam & 175 & 100,0 & 175 & 100,0 \\
\hline
\end{tabular}

Tablo 4 incelendiğinde öğrencilerin okulda, sınıfta ve evde kitaplık/kütüphane bulunma oranının yüksek olduğu görülmektedir. II/illçede kütüphanenin olduğunu belirten öğrenci sayısı ise 36'dır (\% 20,6). Bu durumda öğrenciler sırasıyla okulda, sınıfta ve evde en fazla kütüphane kullanma imkânına sahiptir.

Tablo 5.

Öğrencilerin "Kütüphaneleri hangi amaçla kullanırsınız?" Sorusuna Verdikleri Cevaplara ilişsin Bulgular

\begin{tabular}{lcc}
\hline & $\mathrm{f}$ & $\%$ \\
\hline Ders çalışmak & 3 & 1,7 \\
Boş zamanları değerlendirmek & 11 & 6,3 \\
Ödev yapmak & 29 & 16,6 \\
Kitap okumak & 40 & 22,9 \\
Kitap ödünç almak & 36 & 20,6 \\
Interneti kullanmak & 56 & 32,0 \\
\hline Toplam & 175 & 100,0 \\
\hline
\end{tabular}

Tablo 5'te öğrencilerin kütüphaneleri kullanma amaçlarını gösteren bulgular verilmektedir. Buna göre öğrenciler arasında interneti kullanmak amacıyla kütüphaneye gittiğini belirten öğrenci sayısı en yüksek oranla \% 32'dir. Bunu sırasıyla kitap okumak (\% 22,9), kitap ödünç almak $(\% 20,6)$, ödev yapmak $(\% 16,6)$, boş zamanlarını değerlendirmek $(\% 6,3)$ ve ders çalışmak $(\% 1,7)$ izlemektedir. Ders çalışmak amacını işaretleyen öğrenci sayısının en düşük, interneti kullanmak amacıyla gidenlerin oranının ise en yüksek olması kitap okuma alışkanlığı ile ilgili önemli bir bulgudur.

Tablo 6.

Kitaplıkta/Kütüphanede Bulunan Kitap Türlerine iliş̧kin Bulgular

\begin{tabular}{lcc}
\hline & $f$ & $\%$ \\
\hline Dinî & 60 & 34,3 \\
Ders & 98 & 56,0 \\
Masal & 117 & 66,9 \\
Ansiklopedi & 28 & 16,0 \\
Roman & 69 & 39,4 \\
Şiir & 63 & 36,0 \\
Diğer & 26 & 14,9 \\
\hline Toplam & 175 & 100,0 \\
\hline
\end{tabular}


Evde, sınıfta, okulda ve il/ilçede kitaplık veya kütüphane bulunduğunu belirten öğrencilerden buralarda ne tür kitaplar olduğunu belirtmeleri istenmiştir. Tablo 6'da öğrencilerin verdikleri cevaplara ilişkin bulgular yer almaktadır. 117 öğrenci (\% 66,9) masal, 98 öğrenci (\% 56,0) ders kitapları cevabını vermiștir. 69 öğrenci (\% 39,4) roman, 63 öğrenci (\% 36,0) şiir, 60 öğrenci $(\% 34,3)$ dinî kitapları işaretlemiştir. Kitaplık veya kütüphanede bulunan diğer kitap türleri seçeneğini işaretleyen öğrenci sayısı ise $26^{\prime}$ dır (\% 14,9). Diğer seçeneği ne yönelik verilen yanıtlar ise dergi, hikâye kitabı ve çizgi romandır. Bu verilere göre öğrenciler, kitaplık veya kütüphanede en fazla masal türündeki kitaplar ile karşılaşmaktadır. Araştırma-geliştirmeye dönük bilimsel kitapların, ansiklopedilerin sayısının ise az olduğu görülmektedir.

Tablo 7.

Öğrencilerin "Evinizde anne ve babanızla düzenli olarak yaptığınız belirli bir okuma saati var mı?" Sorusuna Verdikleri Cevaplara ilişskin Bulgular

\begin{tabular}{lcc}
\hline & $\mathrm{f}$ & $\%$ \\
\hline Evet & 71 & 40,6 \\
Hayır & 104 & 59,4 \\
\hline Toplam & 175 & 100,0 \\
\hline
\end{tabular}

Tablo 7'de öğrencilerin evde anne ve babalarıyla düzenli olarak okuma saati yapıp yapmadıklarına ilişkin bulgular gösterilmektedir. 175 öğrencinin $71^{\prime} i(\%$ 40,6) okuma saati yaptıklarını, 104 'ü $(\% 59,4)$ ise evde okuma saati yapmadıklarını belirtmiştir. Hayır diyen öğrencilerin sayısı yüksek olmakla birlikte öğrencilerin \% 40,6'sının aileleriyle okuma saati yapıyor olması okuma alışkanlığııın kazandırıması ve devam ettirilmesi bakımından olumlu bir sonuçtur.

Tablo 8.

Bir Ayda Ortalama Okudukları Kitap Sayısına ilişkin Bulgular

\begin{tabular}{lcc}
\hline & $\mathrm{f}$ & $\%$ \\
\hline 0 & 3 & 1,7 \\
1 & 11 & 6,3 \\
2 & 29 & 16,6 \\
3 & 40 & 22,9 \\
4 & 36 & 20,6 \\
5 ve üzeri & 56 & 32,0 \\
\hline Toplam & 175 & 100,0 \\
\hline
\end{tabular}

Tablo 8'de öğrencilerin bir ayda okudukları kitap sayısı yer almaktadır. Öğrencilerin kitaplık/kütüphane kullanma durumu ve okuma alışkanlıkları arasındaki ilişkiyi belirlemeye yönelik olarak sorulan bu soruya verdikleri cevaplar incelendiğinde 5 ve üzeri kitap okuduğunu belirten öğrenci sayısı en yüksektir. Öğrencilerden 56 'sı (\% 32,0) ayda 5 ve üzeri, 40"ı $(\% 22,9) 3$, 36'sı $(20,6) 4$, $29^{\prime}$ u $(\% 16,6) 2$ ve $11^{\prime}$ i $(\% 6,3) 1$ kitap okumaktadır. Öğrencilerin 3'ü ise $(\% 1,7)$ ayda hiç kitap okumadığını belirtmiştir.

Tablo 9.

Öğrencilerin Kitap Okuma ve Kütüphane Kullanımına Yönelik Görüşleri

\begin{tabular}{|c|c|c|c|c|c|c|c|c|c|c|c|c|}
\hline & \multicolumn{2}{|c|}{$\begin{array}{l}\text { Her } \\
\text { Zaman }\end{array}$} & \multicolumn{2}{|c|}{ Sık Sık } & \multicolumn{2}{|c|}{ Ara Sira } & \multicolumn{2}{|c|}{ Nadiren } & \multicolumn{2}{|l|}{ Asla } & \multirow[t]{2}{*}{$\bar{X}$} & \multirow[t]{2}{*}{$S$} \\
\hline & $f$ & $\%$ & $f$ & $\%$ & $f$ & $\%$ & $f$ & $\%$ & $f$ & $\%$ & & \\
\hline $\begin{array}{l}\text { 1. Annem, } \\
\text { babam bana } \\
\text { kitap hediye } \\
\text { eder. }\end{array}$ & 22 & 12,6 & 36 & 20,6 & 76 & 43,4 & 18 & 10,3 & 23 & 13,1 & 3,09 & 1,156 \\
\hline
\end{tabular}


2. Kitap

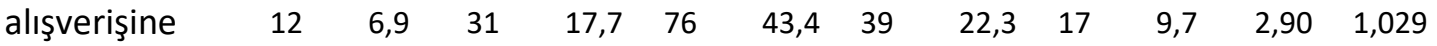
çıkarım.

3. Annem ve

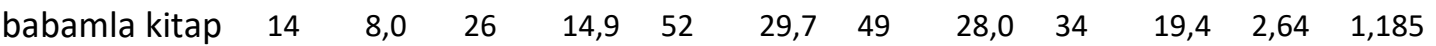
okurum.

4. Yatarken kitap okurum.

$\begin{array}{lllllll}24,0 & 41 & 23,4 & 39 & 22,3 & 31\end{array}$

$\begin{array}{lllll}17,7 & 22 & 12,6 & 3,29 & 1,343\end{array}$

5. Kitapları

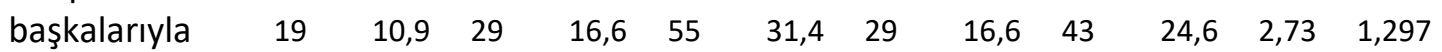
tartışırım.

6. Okul

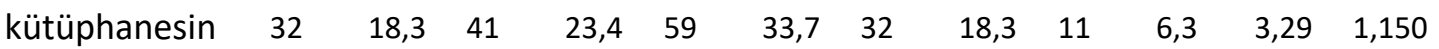
e giderim.

7. Kitapçıları gezerim.

8. il merkez

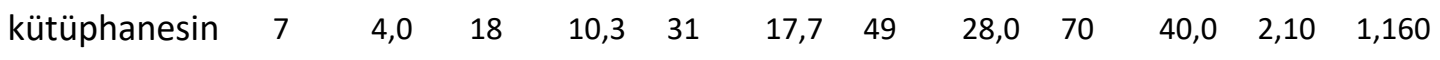
e giderim.

9. Kütüphanelerden kitap $27 \quad 15,4 \quad 40$ $22,9 \quad 48$ $27,4 \quad 35$ $20,0 \quad 25$ $14,3 \quad 3,05 \quad 1,274$ ödünç alırım.

10.Kütüphanenin internet hizmetinden 10 $5,7 \quad 10$ $\begin{array}{llll}5,7 & 32 & 18,3 & 34\end{array}$ $19,4 \quad 89$ $50,9 \quad 1,96 \quad 1,200$ yararlanırım.

11.Annem ve babamla akşamları yaparız.

12.Kütüphanede n kitap almak yerine elektronik $5 \quad 2$ kitap okumayı tercih ederim.

13.Pahalı olduğu için kitap almam.

14.Okuduğum kitapların evde kitaplığımda $113 \quad 64,6 \quad 23$ $13,1 \quad 13$ 7, olmasını isterim.

15.Annem ve babamın okudukları kitapların 22 $12,6 \quad 15$ $8,6 \quad 38$ $21,7 \quad 46$ $26,3 \quad 54$ $30,9 \quad 2,46 \quad 1,342$ türleri benim ilgi alanıma 
girmez.

16.Annem ve

babam

okunan

kitapların

12

$6,9 \quad 15$

$8,6 \quad 14$

$8,0 \quad 23$

$13,1 \quad 111$

$63,4 \quad 1,82 \quad 1,285$

saklanmasını

gereksiz

görür.

17.Kütüphaneye

sadece ders

çalışmak için

$4 \quad 2,3 \quad 4 \quad 2,3 \quad 24$

$13,7 \quad 35$

$20,0 \quad 108$

$61,7 \quad 1,63 \quad 961$

giderim.

18. Kütüphaneye

sadece ödevle

ilgili kitap

10

5,7

$1,1 \quad 26$

$14,9 \quad 37$

$21,1 \quad 100$

$57,1 \quad 1,77 \quad 1,111$

araştırmak

için giderim.

19.Teknoloji

çağında

kütüphaneler

e gerek

olmadığını

düşünüyorum.

20.Okul kütüp-

hanesinde

daha çok çeşit

$14,3 \quad 18$

$10,3 \quad 21$

$12,0 \quad 9$

$5,1 \quad 4,09 \quad 1,277$

okuma

isteğimi

artırır.

21.Il kütüphane-

lerine ulaşım

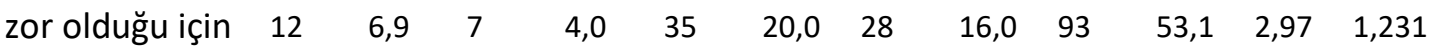

gitmek

istemem.

22.Arkadaşlarım

kütüphaneye

gitmedikleri

5

için ben de

gitmem.

23. Arkadaşlarıml

a

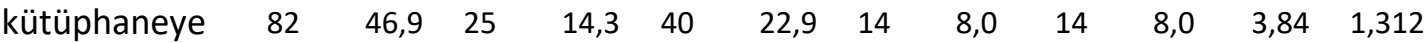
gitmekten

zevk alırım.

24.Ailemle

kütüphaneye

gitmekten

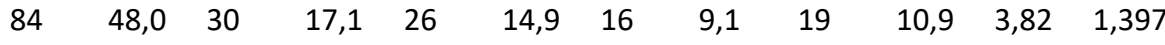

hoşlanırım.

25.Arkadaşlarıma

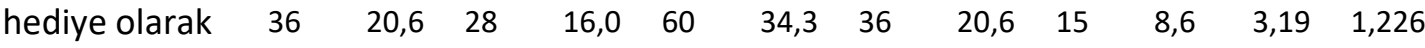

kitap almayı 
tercih ederim.

Tablo 9'da ilköğretim öğrencilerinin okuma kültürü ve kütüphane kullanımına yönelik görüşleri yer almaktadır. Öğrencilerin verdikleri cevaplar içerisinde aritmetik ortalaması en yüksek düzeyde olan görüş; "Okuduğum kitapların evde kitaplığımda olmasını isterim." maddesidir $(\bar{X}=4,21)$. "Okul kütüphanesinde daha çok çeşit kitap olması okuma isteğimi artırır." ( $\bar{X}=4,09)$, "Arkadaşlarımla kütüphaneye gitmekten zevk alırım." (=3,84), "Ailemle kütüphaneye gitmekten hoşlanırım." ( $\bar{X}=3,82)$ maddeleri yüksek ortalamaya sahip olarak öğrenciler tarafından daha fazla kabul gören görüşlerdir.

Uygulanan ankette olumsuz yargı içeren maddeler bulunmaktadır. "Pahalı olduğu için kitap almam." maddesine 116 öğrenci $(\bar{X}=4,33)$, "il kütüphanelerine ulaşım zor olduğu için gitmek istemem." maddesine 93 öğrenci ( $\bar{X}=2,97)$, "Arkadaşlarım kütüphaneye gitmedikleri için ben de gitmem." maddesine ise 121 öğrenci $(\bar{X}=4,42)$ "hiçbir zaman" cevabını vermiştir. Bu durum öğrencilerin kitapların pahalı olmasını okumama gerekçesi olarak görmediklerini ve kütüphaneye gitmek için ulaşım veya arkadaş gibi nedenleri dikkate almadıkları şeklinde yorumlanabilir.

Tablo 10.

Öğrencilerin Cinsiyeti ile Okuma Kültürü ve Kitaplık/Kütüphane Kullanma Görüşleri Arasındaki Ilişsiye Yönelik t-Testi Sonuçları

\begin{tabular}{lllllll}
\hline Gruplar & $\mathrm{N}$ & $\overline{\mathrm{X}}$ & $\begin{array}{l}\text { Standart } \\
\text { Sapma }\end{array}$ & $\mathrm{df}$ & $\mathrm{t}$ & $\mathrm{p}$ \\
\hline KIz & 91 & 2,8910 &, 47852 & 173 &, 178 &, 859 \\
Erkek & 84 & 2,8781 &, 48028 & & & \\
\hline
\end{tabular}

Bağımsız örneklem $t$ testi, kız ve erkek öğrencilerin okuma kültürü ve kitaplık/kütüphane kullanımına yönelik görüşleri arasındaki farkları ortaya koymak için kullanılmıştır. Analiz sonucunda kız $(\bar{X}=2,8910)$ ve erkek ( $\bar{X}=2,8781)$ grupları arasında istatiksel olarak anlamlı bir fark bulunamamıştır. $p=, 859>0.05$ 'tir. Bu sonuca göre kız öğrencilerin okuma kültürü ve kitaplık/kütüphane kullanımına yönelik görüşleri ile erkek öğrencilerin tutumları arasında anlamlı bir farklılık görülmemiştir.

Tablo 11.

Öğrencilerin Babalarının Eğitim Durumu ile Okuma Kültürü ve Kitaplık/Kütüphanelerin Kullanımı Arasındaki Ilişkiyi Belirlemeye Yönelik t-Testi Sonuçları

\begin{tabular}{llllll}
\hline & $\begin{array}{l}\text { Kareler } \\
\text { Toplamı }\end{array}$ & Df & $\begin{array}{l}\text { Kareler } \\
\text { Ortalaması }\end{array}$ & $\mathrm{F}$ & $\mathrm{p}$ \\
\hline Gruplar Arasında & 1,193 & 3 &, 398 & 1,764 &, 156 \\
Grup içi & 38,567 & 171 &, 226 & & \\
\hline Toplam & 39,761 & 174 & & & \\
\hline
\end{tabular}

Tabloda görüldüğü üzere öğrencilerin okuma kültürü ve kitaplık/kütüphane kullanımına yönelik görüşlerinin babalarının eğitim durumlarına göre anlamlı bir farklılık gösterip göstermediğini belirlemek amacıyla yapılan tek yönlü varyans analizi (ANOVA) sonucunda aradaki fark istatiksel olarak anlamlı bulunmamıştır ( $F=1,764 ; p=, 156>0,05)$.

Tablo 12.

Öğrencilerin Annelerinin Eğitim Durumu ile Okuma Kültürü ve Kitaplık/Kütüphanelerin Kullanımı Arasındaki Ilişkiyi Belirlemeye Yönelik t-Testi Sonuçları

\begin{tabular}{llllll}
\hline & $\begin{array}{l}\text { Kareler } \\
\text { Toplamı }\end{array}$ & Df & $\begin{array}{l}\text { Kareler } \\
\text { Ortalaması }\end{array}$ & F & p \\
\hline Gruplar Arasında &, 939 & 3 &, 313 & 1,378 &, 251
\end{tabular}




Grup içi $\quad 38,822 \quad 171$

Toplam $\quad 39,761 \quad 174$

Öğrencilerin okuma kültürü ve kitaplık/kütüphane kullanımına yönelik görüşlerinin annelerinin eğitim durumlarına göre anlamlı bir farklıık gösterip göstermediğini belirlemek amacıyla yapılan tek yönlü varyans analizi (ANOVA) sonucunda anlamlı fark bulunmamıştır $(F=1,378$; $p=, 251>0,05)$.

Tablo 13.

Öğrencilerin Evlerinde Okuma Saati Yapılması Durumu ile Okuma Kültürü ve Kitaplık/Kütüphanelerin Kullanımı Arasındaki Ilişkiyi Belirlemeye Yönelik t-Testi Sonuçları

\begin{tabular}{lllllll}
\hline Gruplar & $N$ & $\bar{X}$ & $\begin{array}{l}\text { Standart } \\
\text { Sapma }\end{array}$ & df & $t$ & $p$ \\
\hline Kız & 91 & 3,1639 &, 38918 & 173 & 7,272 &, 001 \\
Erkek & 84 & 2,6942 &, 43899 & & & \\
\hline
\end{tabular}

Öğrencilerin evlerinde okuma saati yapılması durumu ile okuma kültürü ve kitaplık/kütüphane kullanımına yönelik görüşleri arasındaki ilişkiyi ortaya koymak için Bağımsız örneklem t testi uygulanmıştır. Analiz sonucuna göre $k ı z \quad(\bar{X}=3,1639)$ ve erkek $(\bar{X}=2,6942)$ grupları arasında istatiksel olarak anlamlı bir fark bulunmuştur. $p=, 001<0.05$ olduğundan öğrencilerin evlerinde okuma saati yapılması ile okuma kültürü ve kitaplık/kütüphane kullanımına yönelik görüşleri arasında anlamlı bir farklılık görülmüştür. Söz konusu farklılık kız öğrencilerin lehine gerçekleşmiştir. Bu durumda aile ile birlikte yapılan okuma saatinin öğrencilerin okumaya karşı ilgilerini artırıcı bir durum olduğu yorumu yapılabilir.

Tablo 14.

Ögrrencilerin Okudukları Kitap Sayısı ile Okuma Kültürü ve Kitaplık/Kütüphanelerin Kullanımı Arasındaki Ilişskiyi Belirlemeye ilişkin ANOVA Sonuçları

\begin{tabular}{llllll}
\hline & $\begin{array}{l}\text { Kareler } \\
\text { Toplamı }\end{array}$ & Df & $\begin{array}{l}\text { Kareler } \\
\text { Ortalaması }\end{array}$ & $\mathrm{F}$ & $\mathrm{p}$ \\
\hline $\begin{array}{l}\text { Gruplar Arasında } \\
\text { Grup içi }\end{array}$ & 5,972 & 5 & 1,194 & 5,974 &, 001 \\
\hline Toplam & 33,789 & 169 &, 200 & & \\
\hline
\end{tabular}

Tabloda görüldüğü üzere öğrencilerin okuma kültürü ve kitaplık/kütüphane kullanımı ile ilgili görüşlerinin okudukları kitap sayısına göre anlamlı bir farklılık gösterip göstermediğini belirlemek amacıyla yapılan tek yönlü varyans analizi (ANOVA) sonucunda aradaki fark istatiksel olarak anlamlı bulunmuştur $(F=5,974 ; p=, 001<0,05)$. Anlamlı farklılı̆ın hangi gruplardan kaynaklandığını belirlemek üzere tamamlayıcı post-hoc analiz tekniklerinden yararlanılmıştır. Levene's testi sonucuna göre grup dağılımlarının varyanslarının homojen olduğu saptanmıştır. Çoklu karşılaştırma Tukey testi sonuçları incelendiğinde ayda hiç kitap okumayan, ayda 1 ve 2 kitap okuyan öğrenciler ile ayda 5 ve üzeri kitap okuyan öğrenciler arasında anlamlı farklılık görülmüştür. 5 ve üzeri kitap okuyan öğrenci grubu 0,1 ve 2 kitap okuyan öğrenci grubu lehine istatiksel olarak $(p<, 01)$ düzeyinde anlamlı farklılık belirlenmiştir. Bu durum ayda 5 ve üzeri kitap okuyan öğrencilerin ayda 0, 1 ve 2 kitap okuyan öğrenci grubuna göre okuma kültürü ve kitaplık/kütüphane kullanımı konusunda daha iyi oldukları şeklinde yorumlanabilir. Ayda 3 ve 4 kitap okuyan alt boyutlar arasındaki farklılık istatistiksel olarak anlamlı bulunmamıştır $(p>05)$.

\section{Tartışma ve Sonuç}

Bu çalışmada ilköğretim öğrencilerinin okuma kültürü ve kitaplık/kütüphane kullanma durumlarını belirlemek amaçlanmıştır. Anket sonuçlarına göre öğrenciler en yüksek düzeyde 
"Okuduğum kitapların evde kitaplığımda olmasını isterim." görüşündedir. "Okul kütüphanesinde daha çok çeşit kitap olması okuma isteğimi artırır.", "Arkadaşlarımla kütüphaneye gitmekten zevk alırım.", "Ailemle kütüphaneye gitmekten hoşlanırım.", "Pahalı olduğu için kitap almam.", "il kütüphanelerine ulaşım zor olduğu için gitmek istemem.", "Arkadaşlarım kütüphaneye gitmedikleri için ben de gitmem." maddeleri yüksek ortalamaya sahiptir. Bu durum, öğrencilerin kitap okumaktan ve kütüphaneye gitmekten hoşlandıklarını göstermektedir.

Öğrencilerin anketin birinci bölümünde verdikleri cevaplardan hareketle okulda, sınıfta ve evde kitaplık/kütüphane bulunma oranının yüksek olduğu görülmektedir. Aynı zamanda öğrencilerden kendilerine ait bir kitaplık veya kütüphane olmasını isteyenlerin oranı yüksektir. Öğrencilerin kütüphaneleri kullanma amaçları sırasıyla interneti kullanmak, kitap okumak, kitap ödünç almak, ödev yapmak, boş zamanlarını değerlendirmek ve ders çalışmaktır. Ders çalışmak veya kitap okumak amacıyla kütüphaneye giden öğrenci sayısının interneti kullanmak amacıyla gidenlerin oranından düşük olması kütüphaneyi kullanma amacı açısından düşündürücü bir bulgudur.

Akdağ ve Çoklar (2009), öğrencilerin proje ve performans ödevlerini yaparken yararlandıkları kaynakları araştırdıkları çalışmalarında öğrencilerin en fazla interneti kullandıkları sonucuna varmışlardır. 6. sınıf öğrencileri internetten sonra en çok kütüphaneden yararlandıklarını, 7. sınıf öğrenciler ise kaynak kitaplardan yararlandıklarını belirtmişlerdir.

Öğrenciler evde, sınıfta, okulda ve il/ilçede bulunan kitaplık veya kütüphanelerde en çok masal türünde kitaplar bulunduğunu belirtmişlerdir. Bu türü sırasıyla ders kitapları, roman, şiir ve dinî kitaplar izlemektedir. Araştırmaya dönük bilimsel kaynakların az olması, kütüphanelere olan ihtiyacı daha da artırmaktadır. Şahin ve diğerleri, Erzurum ili örneğinden hareketle yaptıkları çalışmada (2009), öğrencilerin kütüphanelerden zaman zaman yararlandıklarını tespit etmişlerdir. Katılımcılar; sorumluluğun sınıf öğretmenleri, rehber öğretmenler, öğrenciler ve Türkçe öğretmenlerinin üstlendiği kütüphanelerde ve sınıf kitaplıklarında bulunan başvuru kaynaklarının (ansiklopedi vb.), şiir, roman, hikâye vb. kitapların az olduğunu belirtmişlerdir. Çalışmamızda öğrencilerin belirttiği kitap türleri, çeşit açısından zengin olmakla birlikte öğrenciler kitap türlerine yönelik bir eksiklik olduğunu belirtmemişlerdir.

t-Testi ve ANOVA analiz sonuçlarına göre; öğrencilerin cinsiyete göre okuma kültürü ve kütüphane kullanımı arasında anlamlı bir farklııı görülmemiştir. Aynı şekilde anne-babalarının eğitim durumu ile okuma kültürü ve kütüphane kullanımına arasında anlamlı bir farklılık yoktur. Ancak öğrencilerin evlerinde okuma saati yapılması durumu ile okuma kültürü ve kitaplık/kütüphane kullanımı arasında kız öğrencilerin lehine anlamlı bir farklılık görülmüştür. Bu da aile ile birlikte yapılan okuma saatinin önemine işaret etmektedir. Öğrencilerin okuma kültürü ve kitaplık/kütüphane kullanımının okudukları kitap sayısına göre anlamlı bir farklılık gösterdiği tespit edilmiştir. Ayda hiç kitap okumayan, ayda 1 ve 2 kitap okuyan öğrenciler ile ayda 5 ve üzeri kitap okuyan öğrenciler arasında anlamlı farklılık görülmüştür. Bu durum ayda 5 ve üzeri kitap okuyan öğrencilerin ayda 0,1 ve 2 kitap okuyan öğrenci grubuna göre okuma kültürü ve kitaplık/kütüphane kullanımı konusunda daha iyi durumda olduklarını düşündürmektedir.

Yapılan bu araştırmanın sonuçlarına göre öğrencilerin okuma kültürü ve kitaplık/kütüphane kullanmaları arasında önemli bir ilişki vardır. Evinde, sınıfında, okulunda ve yaşadığı bölgede kitaplık veya kütüphane bulunan öğrenciler kitaplarla bir arada olmakta; kitaplar hayatlarının bir parçası hâline gelmektedir. Aynı şekilde aileleri kitap okuyan, evde kitap okuma saatlerine katılan öğrencilerin de okumaya karşı tutumları olumlu gelişmektedir.

Aşıcı ve Özarslan (2002) tarafından yapılan Kocaeli ili örneği çalışmasında ilköğretim öğrencilerinin okul kitaplığını kullanma alışkanlıklarını belirlemek amacıyla öğretmen ve öğrencilere anket uygulanmıştır. Araştırma sonucuna göre, kitaplıkların literatürde tanımlanan standartlardan oldukça uzak olduğu sonucuna varılmıştır. Kütüphane düzeninden sorumlu olan kütüphanecilerin bulunmaması, kitapların kataloglanması, ciltlenmesi ve ayrılmasının yapılmaması, kütüphanenin çoğu zaman kapalı olması öğrencilerin buralardan yararlanmasını engelleyen nedenler arasında belirlenmiştir.

26 ildeki 78 halk kütüphanesinin 2670 kişiden oluşan kullanıcılarına yönelik olarak hazırlanmış “Halk Kütüphanesi Kullanım Araştırması Anketi”nin uygulandığı çalışmada ise 26 ilin halk 
kütüphanelerinin ziyaret edilme sıklıkları, kullanılma amaçları, halk kütüphanelerinde verilebilecek olan eğitimlere yönelik tutumlar araştırılmıştır. Çalışmadan elde edilen verilere göre halk kütüphanelerinden en fazla kitap ödünç almak veya okumak amaçlı olarak yararlanıldığı, kullanıcıların yaşları ile kütüphaneyi ziyaret etme sıklıklarının ters orantılı olduğu, kırsal alanda yaşayanların şehirde yaşayan kullanııılara oranla teknolojiye erişme bakımından daha dezavantajlı konumda bulundukları belirlenmiştir (Al ve Soydal, 2014).

Bu araştırmanın sonuçlarına göre okuma kültürünün kazandırılması ve geliştirilmesi, sınıf, okul veya il kütüphanelerinin öğrenciler için boş zamanlarını değerlendirme, araştırma yapma ve kitap okuma gibi amaçlarla buluşma mekânları hâline getirilmesi, buralardaki kitapların çeşit ve sayılarının artırılması gerekmektedir.

Her il ve ilçede halk kütüphanesinin kurulmasına yönelik çalışmalar yapılmalı, bununla birlikte kamu kurum ve kuruluşlarına da kendi bünyelerinde kütüphane ya da okuma salonları kurma zorunluluğu getirilmelidir. Söz gelimi herhangi bir Bakanlık bünyesinde kurulacak kütüphane tümüyle o alana yönelik yerli ve yabancı kaynaklardan oluşmalı, o alanda araştırma yapan araştırmacılara kaynak sunabilmelidir.

Karadeniz ve Yılmaz tarafından 2017 yılında Ankara'daki halk kütüphanelerinde görev yapmakta olan kütüphanecilerin okuma alışkanlıklarının düzeyini ve niteliğini belirlemeye yönelik yapılan araştırmada görevli personelin düzenli okuma alışkanlığı olduğunu ve alanlarında tecrübe sahibi olduklarını ortaya koymuşlardır. Bu nedenle kütüphanelerde görevlendirilecek personelin okuyucuları doğru yönlendirebilmeleri açısından düzenli okuma alışkanlığı olanlardan seçilmesine öncelik tanınmalıdır.

Okullarda da mutlaka kütüphane olmalı, bununla birlikte sınıf içi kitaplıklar da oluşturulmalı, öğrencilerin buralardan kitap alıp okuyabilmesi sağlanmalıdır. Yılmaz (2019) tarafından yapılan çalışmada çocuk kütüphanelerinin verdiği hizmetler; teknik işlem ve hizmetler, kullanıcı hizmetleri ve yönetici hizmetleri olmak üzere üçe ayırmıştır. Bu nedenle kütüphaneleri sadece ödünç kitap alınan yerler ya da kitap okunup ödev yapılan yerler olarak tanımlamak doğru değildir.

Bu çalışmanın bulgularında da görüldüğü üzere günümüzde internete olan ihtiyaçtan dolayı kütüphaneleri interneti kullanabilmek amacıyla giden öğrenci sayısı fazladır. Bu nedenle kütüphanelerin teknik alt yapısı güçlendirilerek öğrencilerin internet tabanlı araştırma-geliştirme yapabilmelerine imkân sağlanmalıdır. Kütüphanelerin eğitim-öğretimin olmadığı ara dönem ile yaz dönemi için de programları olmalı, öğrenciyi kütüphaneye çekecek etkinliklere (ödüllü bilgi yarışmaları vb.) yer verilmelidir. Yalman tarafından 2020 yılında yapılan "Kütüphanede Verilen 'Kitapların Eğlenceli Dünyası' Eğitim Programının Çocukların Erken Okuryazarlık Becerilerine Etkisinin İncelenmesi" adlı çalışmada da söz konusu programın çocukların erken okuryazarlık becerileri üzerinde olumlu bir etkiye sahip olduğu ortaya konmuştur. Bu nedenle kütüphaneler, günümüz çocuklarına, gençlerine ve yetişkinlere hitap edecek şekilde yeniden çok yönlü olarak tasarlanmalıdır.

\section{Kaynaklar}

Akdağ, H. ve Çoklar, A. N. (2009). İlköğretim 6. ve 7. Sınıf öğrencilerinin sosyal bilgiler dersi proje ve performans görevlerini hazırlarken yararlandıkları kaynaklar, internetin yeri ve karşılaştıkları güçlükler. Adıyaman Üniversitesi Sosyal Bilimler Enstitüsü Dergisi, 2 (2), 1-16.

Al, U. ve Soydal, i. (2014). Kütüphan-e Türkiye projesi: halk kütüphanesi kullanım araştırması, Türk Kütüphaneciliği 28, 3 (2014), 288-307.

Al, U. ; Doğan, G. ; Soydal, İ.; Taşkın, Z. (2017). Herkes için kütüphane projesi başlangıç çalışması. Türk Kütüphaneciliği, 31(1), 11-30, Doi: 10.24146/tkd.2017.0

Aşçı, M. ve Özarslan, H. (2002). İlköğretim 1. kademede okul kitaplığını kullanma alışkanlığı. M.Ü. Atatürk Eğitim Fakültesi Eğitim Bilimleri Dergisi, 15, 45-56.

Aydoğdu, Hamza (2020). Okuma alışkanlığı ve okul kütüphanelerinin bireysel gelişime etkisi üzerine bir değerlendirme. Millî Eğitim Dergisi,225, 201- 226.

Cevher, N. (2015). Ankara'daki halk kütüphanesi çocuk bölümlerinin çocukların okuma alışkanlığındaki rolü. Yüksek Lisans Tezi, Hacettepe Üniversitesi Sosyal Bilimler Enstitüsü. Ankara. 
Kajberg, L. (2013). Halk kütüphanelerinin amacını yeniden tanımlamak: dış teorik çerçeveden esinlenen eleştirel bir yaklaşım. Türk Kütüphaneciliği, 27(2), 253-265.

Karadeniz, ş. ; Yılmaz, B. (2017). Ankara'daki halk kütüphanecilerinin okuma alışkanlığı üzerine bir araştırma, Türk Kütüphaneciliği, 31 (2), 223-244, doi 10.24146/tkd.2017.10.

Karasar, N. (2012). Bilimsel araştırma yöntemi. Ankara: Nobel Yayınları.

Kültür ve Turizm Bakanlığı. (2011). Türkiye okuma kültürü haritası. 23 Nisan 2019 tarihinde http://www.kygm.gov.tr/Eklenti/55,yonetici-ozetipdf.pdf?0 adresinden erişildi.

Ortaş, i. (2014). Türkiye ve dünyada kitap okuma değerlerinin karşılaştırması ve sosyal yaşamımıza etkileri, Türk Kütüphaneciliği, 28(3), 323-337.

Şahin, M., İşcan, A., Maden, S. (2009). İlköğretim öğrencilerinin okul kütüphaneleri ve sınıf kitaplıklarını kullanma durumları (Erzurum ili örneği). Atatürk Üniversitesi Sosyal Bilimler Enstitüsü Dergisi, 13 (2), 183-196.

Yalçınkaya, Y. (2016). Dijital kültür ve dijital kütüphane. Türk Kütüphaneciliği, 30(4), 595-618.

Yalman, F. (2020). Kütüphanede verilen 'kitapların eğlenceli dünyası' eğitim programının çocukların erken okuryazarlık becerilerine etkisinin incelenmesi. Yüksek Lisans Tezi. Karabük Üniversitesi. Karabük.

Yılmaz, Bülent (2019). Çocuk kütüphanesi hizmetleri kılavuzu. İstanbul: Hiperyayın.

Halk Kütüphanesi Hizmeti Gelşşim İçin IFLA/UNESCO ilkeleri 20 Mayıs 2020 tarihinde

https://www.ifla.org/files/assets/hq/publications/archive/the-public-library-service/pg01-

tr.pdf adresinden erişildi.

\section{Extended Abstract}

\section{Introduction}

All scientific advances and progress in all walks of life take place as an outcome of reading. In order to spread the act of reading to help it become reading culture, the reading habit must be acquired individually by a sizeable majority in a society. Reading culture, often confused with reading habit, refers to the social aspect of the act of reading. While the habit is individual, culture emerges as a result of collective effort.

This study aims to reveal the interrelationships among the use of libraries, presence of home libraries and students' reading habits through the opinions of elementary school students.

\section{Method}

The study is descriptive and employed the survey method. It was conducted in the central district of Giresun province with $1755^{\text {th }}$ graders. A questionnaire was developed by the researchers to determine the relationship between students' library use and their reading habits. SPSS 20 software was used for data analysis; frequency, percentage, mean, standard deviation, independent groups t-test and ANOVA analyses were used in the data analysis.

\section{Results and Discussion}

The students' answers to the items in the first part of the questionnaire showed that the percentage of the availability of a library at school, in class and at home was high. The percentage of the students who wanted to have a library of their own was high as well. The reasons for students to use a library were to use the internet, read books, borrow books, do homework, spend free time and study. That the number of the students who went to libraries to use the Internet was higher than the number of the students who went to libraries to read a book or study was a finding that went beyond the intended scope of this study. Students stated that there were mostly fairytale books in their home, classroom, school and district libraries. This genre was followed by textbooks, novels, poetry and religious books respectively.

Based on the t-test and ANOVA results, there was a significant difference in favor of female students among reading hours at home, reading culture and library use. This showed the importance of hours of reading with the family. It was determined that students' reading culture and library usage differed significantly in terms of the number of books they read. There was a significant 
difference among the students who never read any books, read 1-2 books, and read 5 or more books a month. This suggests that the students who read 5 or more books a month were likely to acquire a better reading culture and use libraries more than the students who read no or 1-2 books per month.

The results showed that there was an important relationship between the students' reading culture and library use. Books became a part of the lives of those students who had libraries in their homes, classrooms, schools and districts. Likewise, the attitudes of the students who read books and participated in their home reading hours developed positively.

The reason for the high number of students going to libraries to use the internet is due to the current need for the internet to access knowledge. For this reason, the technical infrastructure of libraries should be constantly updated so that students could make internet-based research under more favorable circumstances. Libraries should also offer hours during the mid-term and summer periods when there is no school and activities that will attract students such as quizzes that offer awards. In conclusion, libraries should be renovated in order to appeal to modern day children, teens and adults. 